\title{
UM ESTUDO SOBRE O MÉTODO CONSTRUTIVO PAREDES DE CONCRETO MOLDADAS IN LOCO - SUA EXECUÇÃO, VANTAGENS E DESVANTAGENS
}

\author{
Vinicius Gabriel Sgobbi ${ }^{1}$ \\ Lucas Rodrigo Miranda ${ }^{2}$
}

https://doi.org/10.47820/recima21.v2i10.915

\begin{abstract}
Resumo: Com o aumento na demanda no setor da construção civil, as empresas buscam métodos eficientes que suprem a grande procura do mesmo em um curto período. $\mathrm{O}$ trabalho tem como objetivo analisar o método construtivo Paredes de Concreto, analisando outras dissertações sobre o tema. No presente trabalho será caracterizado o método construtivo, suas principais etapas, as vantagens e desvantagens de se moldar as paredes de concreto in loco, a classificação das fôrmas, do concreto a ser utilizado, e o acabamento desta construção. Este tipo de sistema construtivo tem seu custo maior comparado com outros sistemas construtivos, porém, suas vantagens como, menor desperdício de matéria prima, rápida execução e da não necessidade de mão de obra especializada pode colocará o sistema construtivo paredes de concreto moldadas in loco em grande crescimento na sua utilização nos próximos anos.
\end{abstract}

Palavras-chave: Fôrmas, in loco, método construtivo, paredes de concreto.

Abstract: With the increase in demand in the civil construction sector, companies are looking for efficient methods that meet the high demand for it in a short period. The work aims to analyze the Concrete Walls constructive method, analyzing other dissertations on the subject. The present work will characterize the construction method, its main steps, the advantages and disadvantages of molding the concrete walls in loco, the classification of the forms, the concrete to be used, and the finishing of this construction. This type of construction system has a higher cost compared to other construction systems, however, its advantages such as less waste of raw material, fast execution and the lack of specialized labor can place the construction system in loco cast concrete walls growth in its use in the coming years.

Key-words: Formwork, in loco, construction method and concrete walls.

\footnotetext{
${ }^{1}$ Graduando do Curso de Engenharia Civil da Universidade de Araraquara- UNIARA. Araraquara-SP. Email: vinicius_sgobbi@hotmail.com

${ }^{2}$ Orientador. Docente Curso de Engenharia Civil da Universidade de Araraquara- UNIARA. AraraquaraSP.E-mail: lmiranda@uniara.edu.br
} 


\section{INTRODUÇÃO}

No método construtivo, as paredes e lajes são moldadas a partir de fôrmas montadas no local e preenchidas com concreto. É um sistema industrializado e garante as condições técnicas ideais para a produção de moradias em grande escala em um curto período. Atende à construção de empreendimentos de médio e grande porte. $O$ método apresenta uma ótima alternativa para empreendimentos que exigem um curto prazo de entrega, economia e mão de obra otimizada.

Com base nos dados de pesquisas realizadas pela Câmara Brasileira da Indústria da Construção (Cbic), a previsão para este ano é considerada boa. Para 2021, a indústria deve ter o maior crescimento em 8 anos, o Produto Interno Bruto (PIB) do segmento deve crescer 4\% em 2021, após uma retração de 2,8\% em 2020. Há uma alta expectativa nos próximos anos para o mercado da construção civil.

De acordo com Ponzoni (2013), um dos métodos inovadores e amplamente utilizado nas obras de apelo social é o sistema construtivo paredes de concreto, que é moldada in loco. De início, o uso deste método gera um custo inicial elevado, porém quando se observa as vantagens, como por exemplo, velocidade no processo construtivo, o investimento é compensado.

Grandes construtoras já estão usando o método construtivo Paredes de Concreto moldadas no local, devido as suas inúmeras vantagens, principalmente pela rapidez na execução do projeto, uso racional dos materiais construtivos, baixa geração de resíduos, maior uniformidade, podendo atender a alta demanda de obras com qualidade. Neste método, as paredes são feitas na espessura final, assim, eliminando o reboco

Corail (2007), diz que no Chile, essa técnica é usada há mais de 40 anos, e a chave para o seu uso no país foi o terremoto de 1985. Um estudo mostrou que, os 230 edifícios analisados, todos eles com paredes de concreto, existentes na cidade de Viña Del Mar no período das vibrações, a maioria deles suportou os abalos sísmicos sem apresentar danos estruturais. A preferência por esse 
sistema construtivo em regiões de terremoto se deve ao fato de as paredes proverem resistência e rigidez, o que limita os danos causados pelos terremotos.

Com bases nos dados de Cimento Itambé (2018), esse método vem ganhando cada vez mais espaço entre os países latino-americanos, tais como, México, Costa Rica, Colômbia, Bolívia e Venezuela. Já existente no Brasil, como por exemplo, as habitações do programa Minha Casa Minha Vida.

O trabalho tem como objetivo analisar o método construtivo Paredes de Concreto, mostrar os modelos de fôrmas mais usadas, bem como apresentar suas vantagens e desvantagens e esclarecer os procedimentos da NBR 16055:2012, Paredes de concreto moldadas no local para a construção de edificações - Requisitos e procedimentos.

Paramento desenvolvimento deste trabalho foi realizada pesquisas bibliográficas sobre paredes de concreto, revistas e a NBR 16055:2012. A hipótese deste trabalho é comprovar a importância do método, que já vem sendo usado por várias empresas na construção de conjuntos habitacionais e edificações com pavimentos padronizados.

No método Paredes de Concreto moldada in loco, qual dos modelos de fôrmas é mais vantajoso ser utilizado para empreendimentos que têm alta repetitividade?

O melhor modelo de fôrmas seria a Tecwall (fôrmas metálicas), porque só é vantajosa a utilização desse modelo quando há uma grande repetitividade de construções, pois esse modelo de fôrma possui um valor alto para utilizar em poucas construções.

\section{BREVE CARACTERIZAÇÃO DOS MÉTODOS CONSTRUTIVOS}

A grande demanda por habitações de interesse social forçou o mercado a investir nos chamados sistemas inovadores, que apresentam processos construtivos racionalizados, que buscam um menor consumo de mão de obra e otimização do tempo de execução através do aumento do uso de produtos e processos industrializados (CBIC, 2013). 
O sistema construtivo de paredes de concreto oferece produtividade, economia e qualidade quando o problema é a redução do déficit habitacional (MISURELLI E MASSUDA, 2009).

Esse sistema possibilita a construção de casas térreas, edifícios de 8 pavimentos padrão com esforços de compressão e até 30 pavimentos considerados casos especiais e específicos. (MISURELLI E MASSUDA, 2009).

Misurelli e Massuda (2009,) afirmam que primeiramente deve-se avaliar 0 terreno e o tipo de empreendimento e que "a seleção deve considerar a segurança, a estabilidade e a durabilidade, além do alinhamento necessário para a produção"

Sacht (2008) recomenda que se utilize fundação tipo radier, porém sapatas corridas, blocos de travamento de estacas e tubulões também podem ser usados segundo Missurelli e Massuda (2009).

A Associação Brasileira de Cimento Portland (2002) informa que as armaduras nesse sistema têm a função de resistir as tensões iniciais geradas pela retração do concreto. Além de também servir para resistir aos esforços de flexo torção nas paredes por ações externas e esforços devido à variação da temperatura externa.

Deve-se utilizar espaçadores para garantir o posicionamento dos painéis e das armaduras de acordo com o projeto, principalmente alinhamentos e espessuras (ABCP, 2002).

Corsini (2012) afirma que "Um dos pontos cruciais do sistema é o custo da forma. Geralmente é de alumínio, um material nobre. Mas é uma fôrma que pode ser utilizada muitas vezes, de 500 até duas mil vezes".

\section{O SISTEMA CONSTRUTIVO}

Segundo Sacht (2008), esse método foi documentado pela primeira vez no Brasil em 1979, implantado pela COHAB, empresa imobiliária mineira de Santa Lúcia, das quais 46 casas foram construídas no Conjunto Habitacional Carreira Comprida. Vale destacar que o peso fina da estrutura é inferior ao método tradicional de alvenaria, economizando assim na fundação. Outra 
vantagem apontada por Sacht (2008) é que há pouco desperdício de material, a tinta é aplicada diretamente na parede e os dispositivos elétricos e hidráulicos são embutidos. No entanto, apareceram rachaduras na casa, fazendo com que os reparos excedessem rapidamente o orçamento previso.

De acordo com a Associação Brasileira de Cimento Portland (2002), o sistema construtivo foi utilizado nas cidades de Natal (RN) na década de $80 \mathrm{e}$ Manaus (AM), também em casas populares. No Brasil, aproximadamente 40.000 casas foram construídas com paredes de concreto em 2002.

ABCP (2008) afirma que à medida que mais e mais casas populares são construídas, as paredes de concreto têm alcançado bons resultados e os construtores começaram a se interessar mais por novas tecnologias.

Com base nos dados da NBR 16055:2012, paredes de concreto é um "elemento estrutural autoportante com comprimento maior que dez vezes a espessura e capaz de suportar carga no mesmo plano de parede".

Nesse sistema construtivo, a estrutura e a vedação são formadas por um único elemento, a parede de concreto, que é formada no local. É um método racionalizado, e nele permite um planejamento completo e detalhado da obra, para que se possa executar a obra de forma correta, evitando custos e atrasos desnecessários, elimina processos artesanais e improvisados, menos trabalhadores no canteiro de obra, facilita o treinamento de mão de obra, reduz prazo de execução e aumenta os indicadores de produtividade. Possui grande vantagem na produção em alta escala sem perder a sua qualidade. Por isso, é de muita importância conhecer e dominar todas as etapas dessa técnica construtiva.

Os dispositivos elétricos e hidráulicos são embutidos na alvenaria antes do lançamento do concreto, que se infiltra através das fôrmas instaladas pelo perímetro delimitado no projeto. Nessa etapa, as esquadrilhas podem ser instaladas, podendo ser posicionadas após a concretagem.

\section{AS PRINCIPAIS ETAPAS NA EXECUÇÃO}


Em obras com muitas repetições, é comum, que, este método exija o nivelamento da fundação, geralmente radier, para as fôrmas serem montadas. Como as paredes são moldadas numa única etapa e não é possível usar vibradores durante o processo de concretagem, o concreto deve ter uma alta fluididade e plasticidade. Os pontos a partir de onde o concreto será lançado nas fôrmas são previstos com a finalidade de espalhar uniformemente o material, assim, evitando vazios de concretagem.

Fundação: A escolha do tipo de fundação depende das condições locais de cada empreendimento, e precisa atender todos os aspectos de segurança, estabilidade e durabilidade. Deverão ser realizadas com alinhamento e nivelamento rigorosos, permitindo a correta montagem do sistema de fôrmas para uma perfeita execução das paredes de concreto. O sistema de fundações deve ser robusto para que evitem deformações e criem tensões indesejadas nas paredes, diferentemente das estruturas convencionais que tem elementos que concentram as cargas, vigas e pilares.

É ideal executar uma laje/piso na cora do terreno, para que constitua um apoio as formas e elimina a possibilidade de se trabalhar no terreno bruto. Também vale citar que essa laje/piso seja construída excedendo a dimensão igual à espessura dos painéis externos das fôrmas, com isso, possibilita o apoio e facilita na hora da montagem dos moldes. Se por acaso for adotado a fundação do tipo radier, recomenda-se construir a calçada externa na mesma concretagem.

De acordo com o detalhamento do projeto, as fundações são construídas com tubulações de água e outros pontos de conexão embutidas nela. Por isso é muito importante fazer todo o posicionamento das tubulações, conforme o projeto de instalações.

Não há restrições quanto ao tipo de fundação a ser utilizado. Podem ser empregados os sistemas de fundações em sapata corrida, radier (laje de apoio) e blocos de travamento para estacas ou tubulões. A escolha varia de acordo com os dados obtidos pela topografia do terreno, de acordo com suas especificações. 


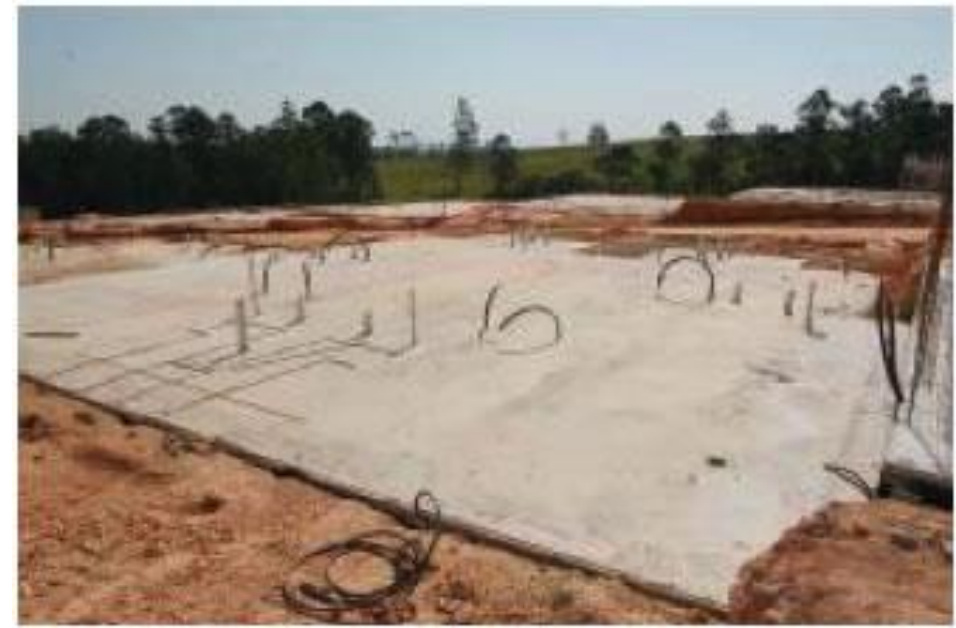

Figura1 - Fundação Radier

Fonte: (COMUNIDADE DA CONSTRUÇÃO, 2021)

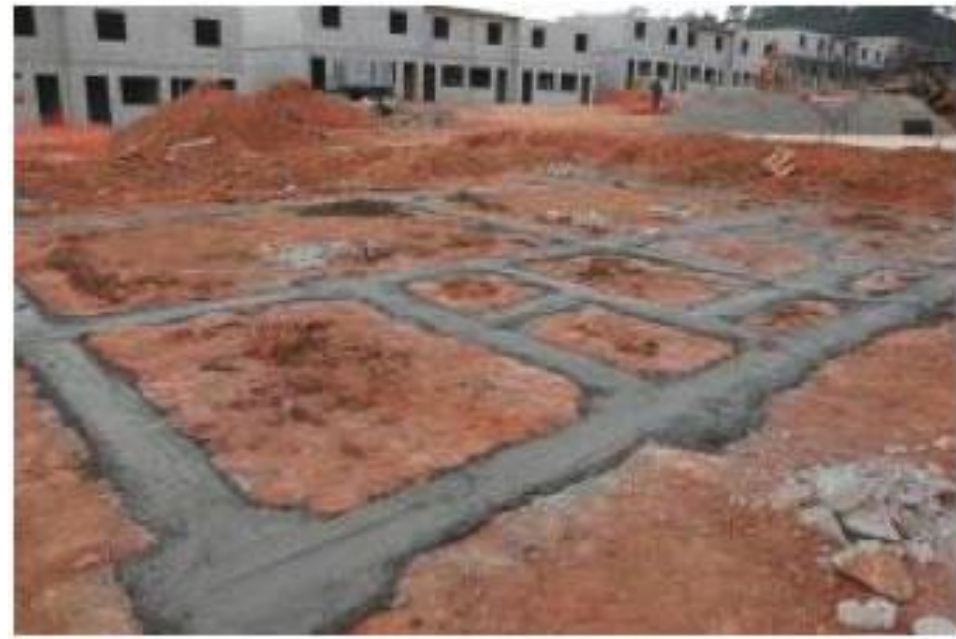

Figura 2 - Fundação Sapata Corrida

Fonte: (COMUNIDADE DA CONSTRUÇÃO,2021)

Recomenda-se a realização da cura úmida do concreto por um período mínimo de 7 dias para as fundações em laje tipo radier.

A concretagem das fundações tipo radier é feita de forma convencional, diretamente do caminhão betoneira, sobre uma lona plástica que cobre a camada nivelada pela brita 1, com espessura de $3 \mathrm{~cm}$.

Montagem das armaduras: devem ser seguidas as caracterizações do projeto estrutural, para a montar as telas soldadas e dos reforços. 
No sistema paredes de concreto existem três requisitos básicos: resistir a esforços de flexo-torção nas paredes, controlar a retração do concreto e estruturar e fixar as tubulações de elétrica, hidráulica e gás. É de grande importância que todos os projetos de instalações estejam desenvolvidos e concluídos na etapa de fundações para evitar retrabalho.

Inicialmente conta com à montagem da armadura principal. Após, acrescentado as armaduras de reforços, ancoragens de cato e cintas. Feito isso, será colocado os espaçadores plásticos, servem para assegurar a localização das telas e a geometria dos painéis para ir de acordo com os dados passados no projeto.

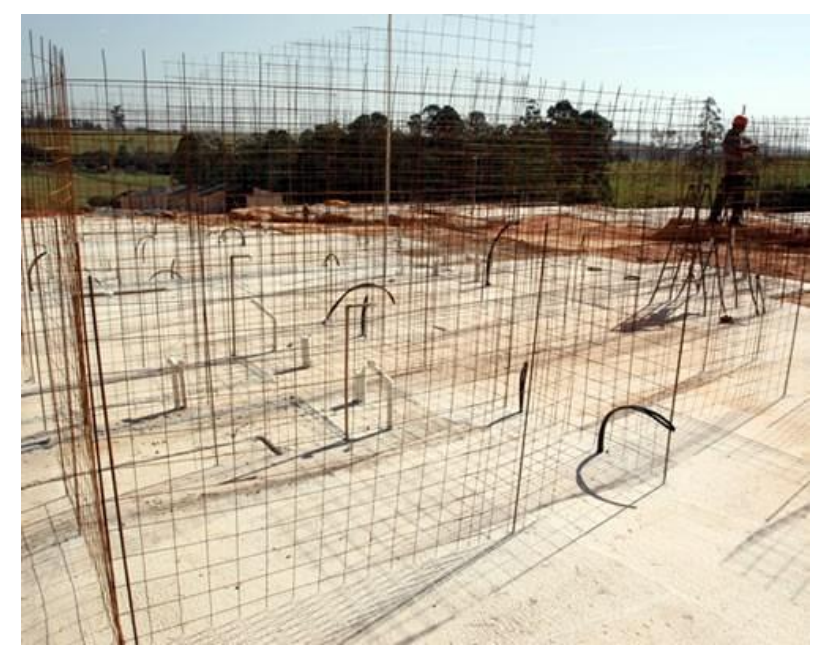

Figura 3 - Montagem das armaduras da parede de concreto Fonte:(CLUBE DO CONCRETO, 2021)

Montagem das fôrmas: É ideal iniciar a montagem dos painéis através da parede hidráulica (banheiro ou cozinha), primeiro coloque as cantoneiras em forma de "L", e depois, coloque os painéis da face interna da parede hidráulica, com isso, permite posicionar as tubulações exatamente no centro da parede. Os painéis devem ser montados em ordem, usando conectores como clipes ou pinos. A montagem deve obedecer à ordem indicada na planta conforme 0 projeto. 
Podem ser feitas de duas formas a sua montagem:

Painéis internos primeiro e logo após os externos - monta um dos lados das fôrmas, continua montando as armaduras, reforços, instalações em geral e esquadrilhas, e após fecha a fôrma com a montagem do outro lado dos painéis.

Painéis internos e externos juntos - toda armadura, reforços e as instalações em geral são montadas primeiro e após a montagem das esquadrilhas e dos painéis de fôrmas interno e externos simultaneamente.

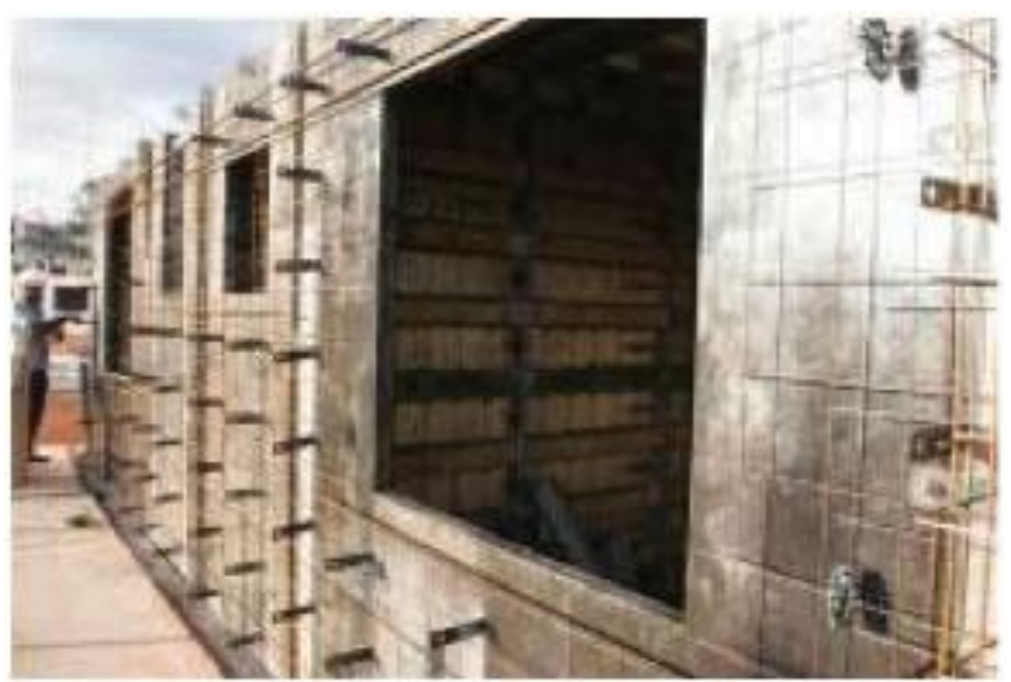

Figura 4 - Fôrmas montadas

Fonte: (COMUNIDADE DA CONSTRUÇÃO, 2021)

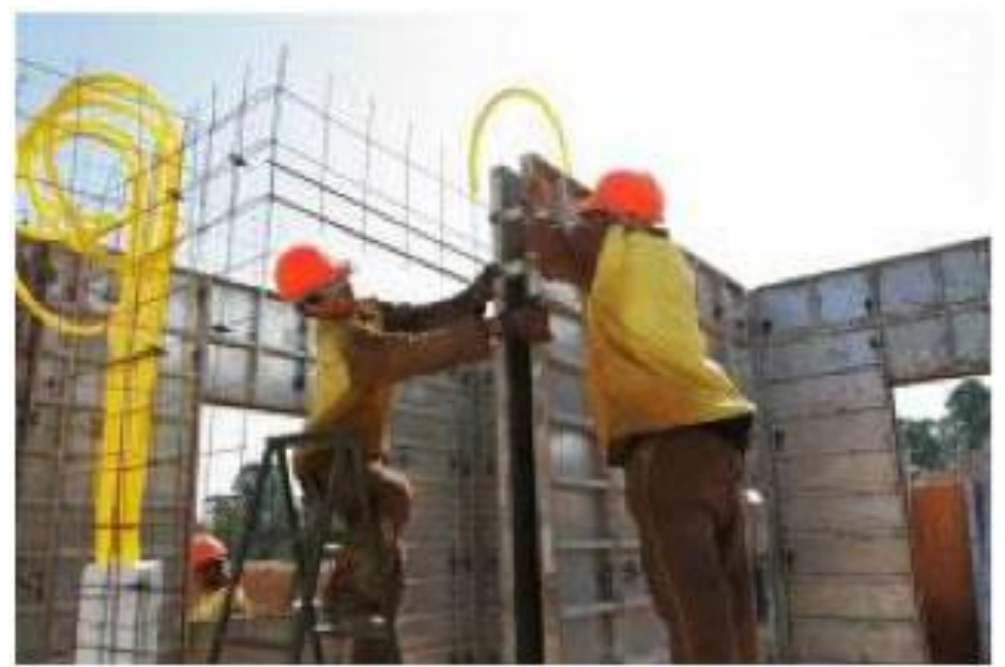

Figura 5 - Fechamento dos painéis Fonte: (COMUNIDADE DA CONSTRUÇÃO, 2021) 
Devem ser montados os painéis e conectados, ambos os lados, com o uso de clipes ou pinos. Deve ser montada seguindo as distribuições indicadas na planta de execução.

Posicione as esquadrias (portas e janelas) e coloque as escoras prumadoras, que facilitam na montagem, permanecendo os painéis soltos "em pé", e posteriormente será feito o ajuste cuidadosamente do prumo das paredes.

Os prumadores auxilia na montagem e permite o ajuste milímetro no prumo das paredes.

Instalações: Pós a desforma, no interior das paredes terá embutidas nelas todos os elementos previstos em projeto, como por exemplo: caixilho, tubulações elétricas, tubulações hidráulicas entre outros.

Caixilhos - Os elementos de esquadrilhas (batentes de portas e caixilhos de janelas) podem ser colocados simultaneamente à montagem dos demais componentes da parede. É recomendado embutir esses elementos nos painéis de fôrmas, com isso, reduz o uso de mão de obra. Obviamente, todos os elementos de esquadrilhas devem ter a espessura igual ou inferior à largura das paredes. A grande repetitividade dos projetos é uma característica desse método construtivo, com isso, as janelas e portas irá sempre estar posicionadas nos mesmos painéis de fôrmas.

Rede hidráulica - Os pontos de conexão da rede devem ser marcados nos painéis de fôrmas de parede já na primeira montagem, marcando sempre as mesmas posições nas várias operações futuras de execução das casas ou edifícios.

Amarre as armaduras e coloque espaçadores no meio da rede de tubos hidráulicos e das faces dos painéis, assim, garantindo a cobertura e 0 posicionamento dos componentes. É necessário proteger as caixas elétricas contra a entrada de concreto e obstrução dos dutos. É possível utilizar produtos próprios, que contam com tampas removíveis. Kits hidráulicos podem aumentar a produtividade, mas exigem testes antes da instalação.

Rede elétrica - Segue o mesmo sistema apresentado para a rede hidráulica. As caixas de interruptores, tomadas, luzes etc. são fixadas nos 
painéis de fôrmas de paredes através de gabaritos, de acordo com a posição indicado no projeto.

Fixe os eletrodutos às armaduras, para que não sejam deslocados durante o lançamento do concreto. E coloque espaçadores entre a rede de dutos e os moldes das paredes, a fim de garantir posicionamento e a cobertura. Nas caixas elétricas, para evitar a entrada de concreto e a obstrução dos dutos elétricos, elas podem ser completadas com papel ou pó de serra.

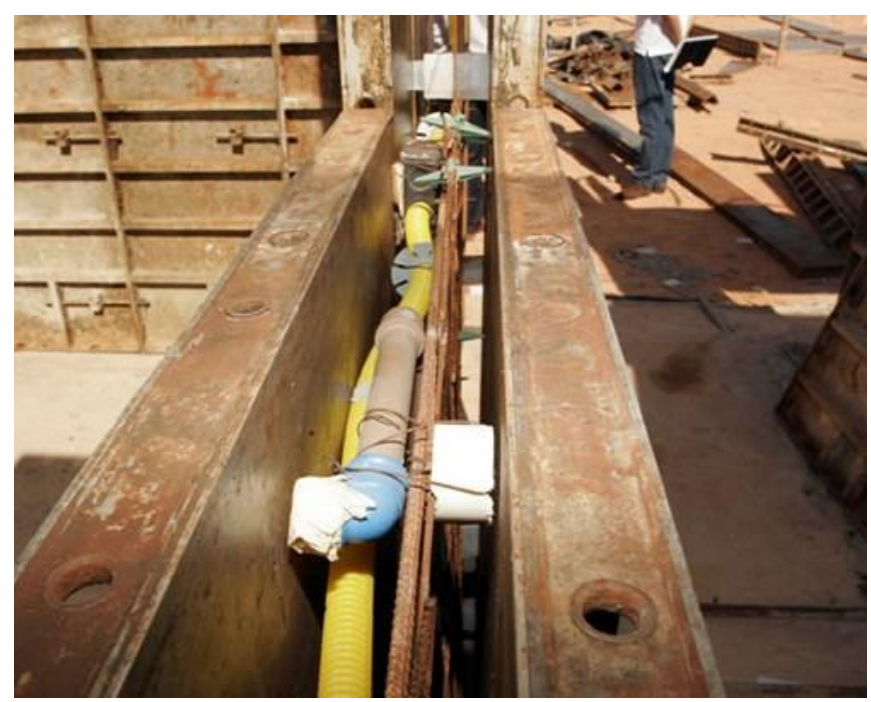

Figura 6 - Instalações hidráulicas Fonte: (CLUBE DO CONCRETO, 2021)

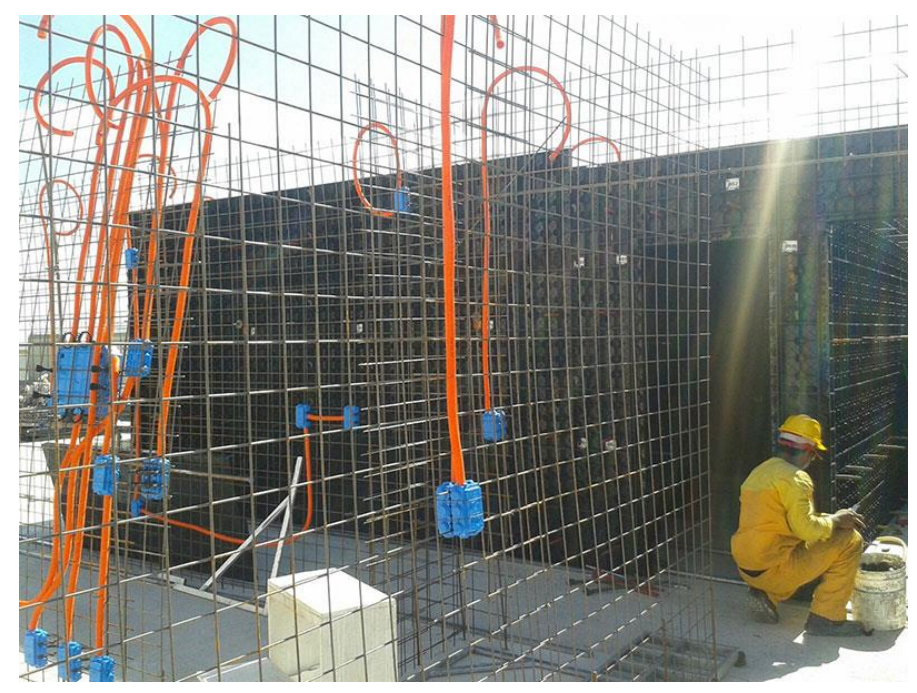

Figura 7 - Instalações elétricas Fonte: (MODULAR, 2021) 
Concretagem: Na chegada do concreto na obra, é essencial conferir o documento, certificando-se de que a descrição do material corresponde ao que foi solicitado e se as descrições da obra estão corretas. Confira o lacre da bica antes deste ser quebrado e não receba o concreto caso houver divergências. Antes de lançar o concreto, verifique se ele está com a consistência esperada e se não ultrapassou o abatimento (slump) ou o espalhamento (flow) limite especificado no documento da entrega.

Tome as medidas necessárias para manter a uniformidade do concreto. Para peças estreitas e altas, o concreto deve ser lançado por janelas abertas nas laterais, ou através de funis ou trombas. O concreto ideal para este sistema é o autoadensável. Sua excelente fluidez e plasticidade eliminam a necessidade de vibração e sua alta aderência evita a separação dos materiais.

Antes da distribuição do concreto nas fôrmas deve haver um planejamento detalhado, levando em consideração as características do concreto que será utilizado e o layout do canteiro para a concretagem das fôrmas. No concreto autoadensável, precisa considerar a fluidez do material. A concretagem das paredes de concreto obedece a um critério de escolha de pontos, com isso, a massa fluída possa caminhar homogeneamente pelas fôrmas e preencher todos os vazios. A concretagem das paredes deve ser iniciada por um dos cantos da edificação, até que uma parte das paredes próximas esteja totalmente cheias. Em seguida, para o canto oposto até completar os quatro cantos.

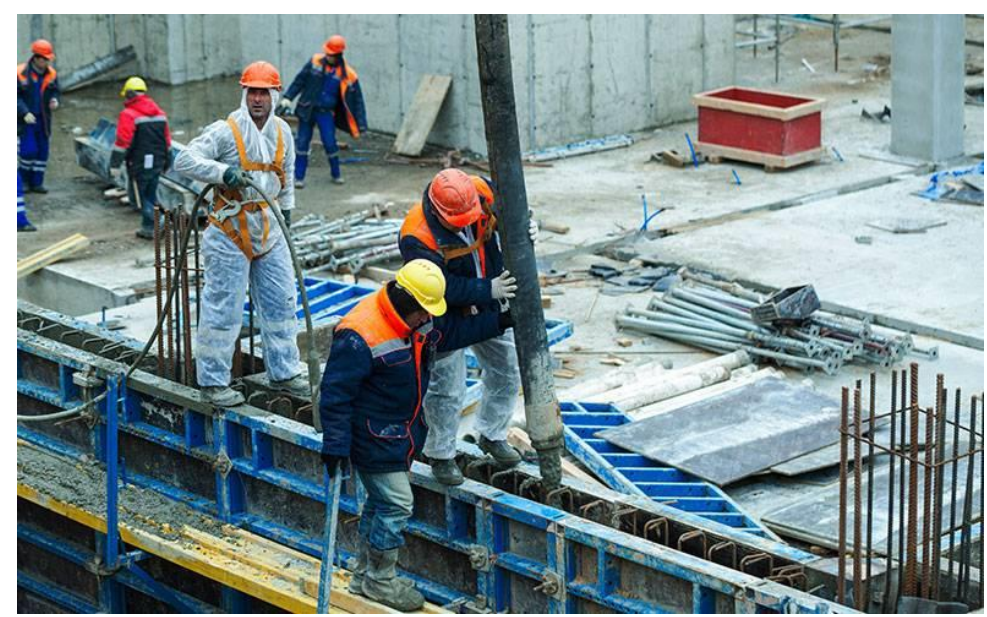

Figura 8 - Lançamento do concreto nas fôrmas Fonte: (MAPA DA OBRA, 2021) 
Desforma: Apenas quando o concreto atingir a resistência e a elasticidade previstas no projeto.

A NBR 16055 especifica que "A cura do concreto deve sempre ser executada, e [...] Quando mais cedo for feita a cura, menor a possibilidade de surgirem fissuras superficiais devido à grande área exposta" (ASSOCIAÇÃO BRASILEIRA DE NORMAS TÉCNICAS, 2012).

A remoção do escoramento e das fôrmas deve ser feita sem batidas, para evitar a aparição de fissuras por ação mecânica. Normalmente ocorre em até 24 horas após a concretagem, depois da verificação da resistência mínima do concreto.

Depois da desmontagem, os painéis devem ser colocados no chão, próximo à fundação da próxima habitação a ser construída, e ser cuidadosamente limpas, incluindo a retirada completa da película de argamassa. Na limpeza pode utilizar jatos fortes de água, pois é preciso regular a pressão da água, para não danificar o acabamento das formas. Também pode ser feio a limpeza dessa crosta com água e escova ou espátula plástica, esse é o método mais demorado. Esse trabalho de remoção deve ser cuidadoso, assim, garante a vida útil das formas.

Com a limpeza feita, aplique o desmoldante. O produto precisa ser adequado a cada superfície, evitando-se que o concreto grude na fôrma e deixe resíduos na superfície das paredes.

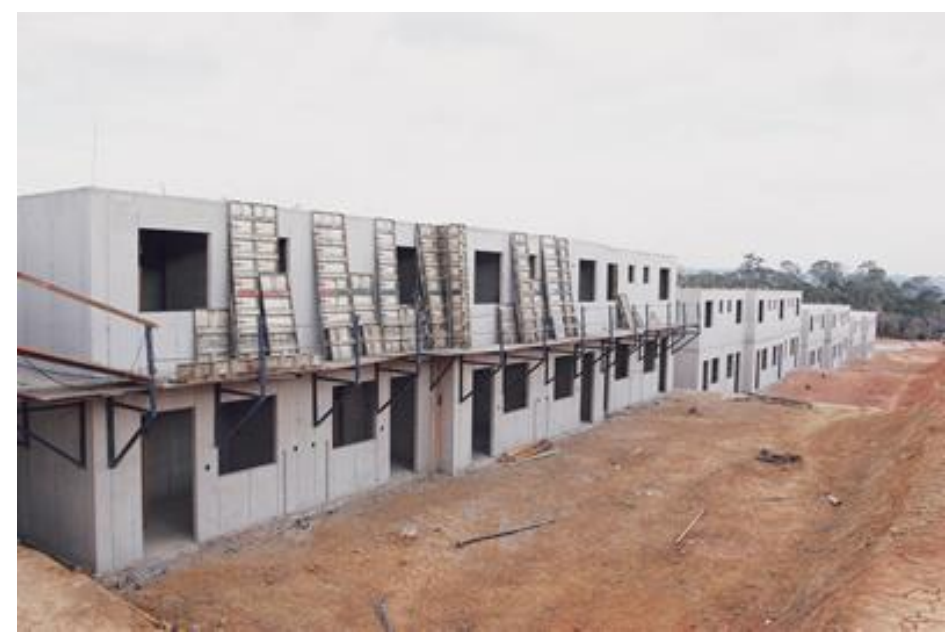

Figura 9 - Desforma

Fonte: (COMUNIDADE DA CONSTRUÇÃO, 2021) 


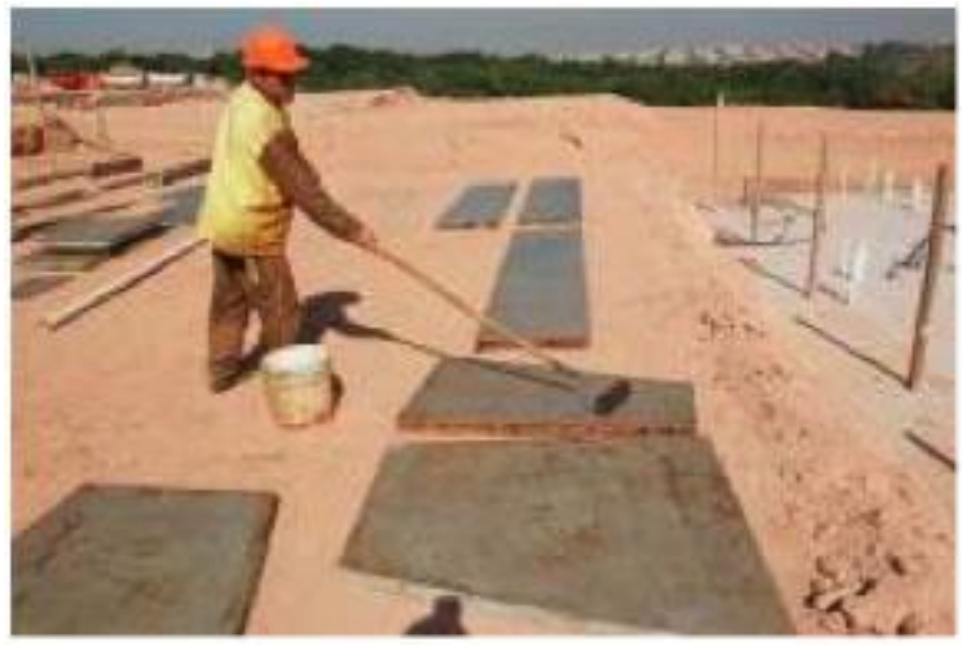

Figura 10 - Aplicação do desmoldante

Fonte: (COMUNIDADE DA CONSTRUÇÃO, 2021)

Cura: A cura do concreto é recomendada a começar o mais cedo possível, assim, diminui o risco do surgimento de fissuras superficiais, principalmente em lajes.

O método mais comum de cura é por molhagem: umedecimento do concreto com água. Para isso é necessário, por pelo menos três dias, que a face do concreto esteja continuamente em contato com a água - molhando a parede pelo menos 5 vezes ao dia (em regiões quentes e com grande incidência de ventos esse período deve ser maior).

\section{VANTAGENS E DESVANTAGENS}

Uma grande vantagem, que por sinal também é desvantagem, são as etapas de projeto, que devem ser elaboradas com bastante antecedência, assim, evitar interferências dos sistemas.

Outra desvantagem é a parte das instalações elétricas, que devem haver o mínimo necessário, para evitar grandes volumes de tubos nas paredes. Também há uma limitação de paredes sem travamentos, que poderá aumentar consideravelmente a espessura mínima a esbeltez.

Segundo Corrêa (2012) a parede de concreto apresenta diversas vantagens em relação aos sistemas construtivos convencionais, como por exemplo: 
- Alta velocidade de produção;

- Maior industrialização do processo;

- Maior controle de qualidade, dado pela utilização de materiais com maior controle tecnológico;

- Sistema racionalizado;

- Baixa geração de resíduos;

- Econômico para empreendimentos de alta repetitividade, como condomínios e edifícios residenciais;

- Maior uniformidade.

Corrêa (2012) diz ainda que: entretanto, o sistema apresenta algumas desvantagens, tais como:

- Baixa flexibilidade arquitetônica;

- Paredes não removíveis;

- Necessidade de mão de obra qualificada;

- Dificuldade de manutenção nas instalações hidráulicas e elétricas (embutidas na parede);

- Antieconômica para empreendimentos de baixa repetitividade ou de grande complexidade arquitetônica;

- Mais suscetível à retração do que as estruturas convencionais.

\section{FÔRMAS}

Com base nos dados estabelecidos pela NBR 16055:2012, as fôrmas devem ser construídas e projetadas visando a ter:

a) resistência a ações a que possa ser submetido durante o processo de construção, considerando:

- Ações ambientais;

- Carga da estrutura auxiliar; 
- Cargas das partes da estrutura permanente a serem suportadas pela estrutura auxiliar até que o concreto atinja as características estabelecidas pelo responsável pelo projeto estrutural para remoção do escoramento;

- Efeitos dinâmicos acidentais produzidos pelo lançamento e adensamento do concreto, em especial o efeito de adensamento sobre o empuxo do concreto nas fôrmas das paredes, respeitados os limites estabelecidos em 19.6 e 19.7

b) rigidez suficiente para assegurar que as tolerâncias especificadas para a estrutura das paredes de concreto em 19.3.4 e nas especificações do projeto sejam satisfeitas e a integridade dos elementos estruturais não seja afetada;

c) estanqueidade e conformidade com a geometria das peças que estão sendo moldadas.

O formato, a função, a aparência e a durabilidade de uma estrutura de parede de concreto permanente não podem ser prejudicados devido a qualquer problema com as fôrmas, o escoramento, os aprumadores ou sua remoção.

Neste método construtivo, os modelos de fôrmas mais utilizadas são:

Fôrmas metálicas: A utilização desse modelo de fôrma só é vantajosa quando há uma grande repetitividade de construções do mesmo padrão, pois esse modelo de fôrma tem um valor elevado para a utilização de poucas construções. Com o manuseio correto desse modelo de fôrma, todos os cuidados e uma boa manutenção, elas podem ser utilizadas de 500 a 2.000 vezes.

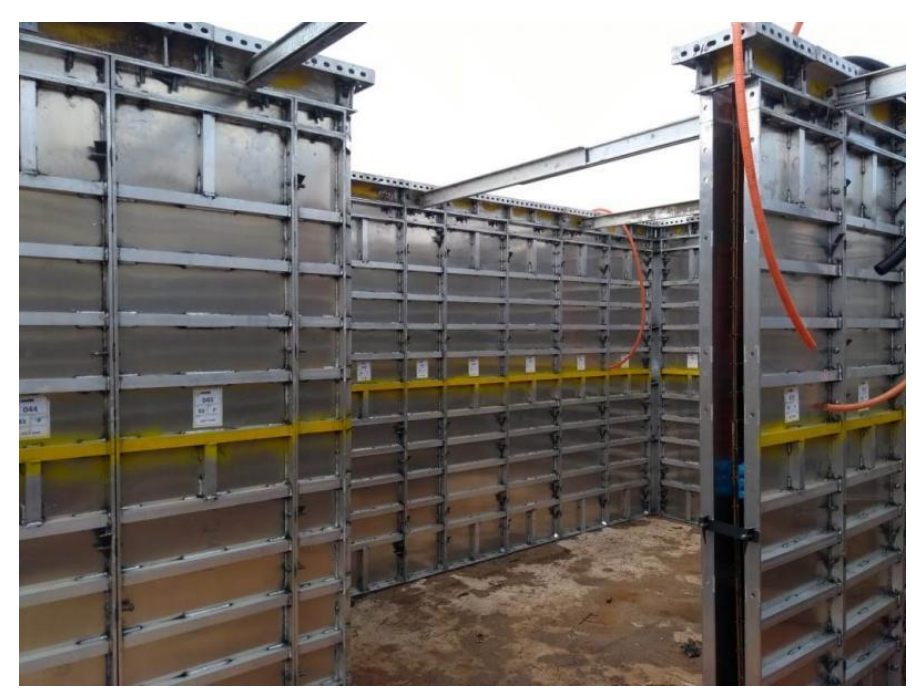


Fôrmas plásticas: desenvolvido para atender obras de baixo custo, diminuir a utilização de madeira, aumentar a rapidez e a eficiência na execução e reduzir o valor da mão de obra. Elas são fabricadas com plástico resistente à umidade e as agressões do concreto. Esse modelo de fôrma é feito com material reciclável, tornando as mesmas também reciclável.

São moldes leves, assim, facilitando o manuseio no canteiro de obras, portanto, permitindo a economia de recursos.

De acordo com a Tecwall, pode fazer a reutilizações das fôrmas entre 50 a 200 vezes, podendo variar bastante em função dos cuidados adotados, manuseio e a correta manutenção das peças.

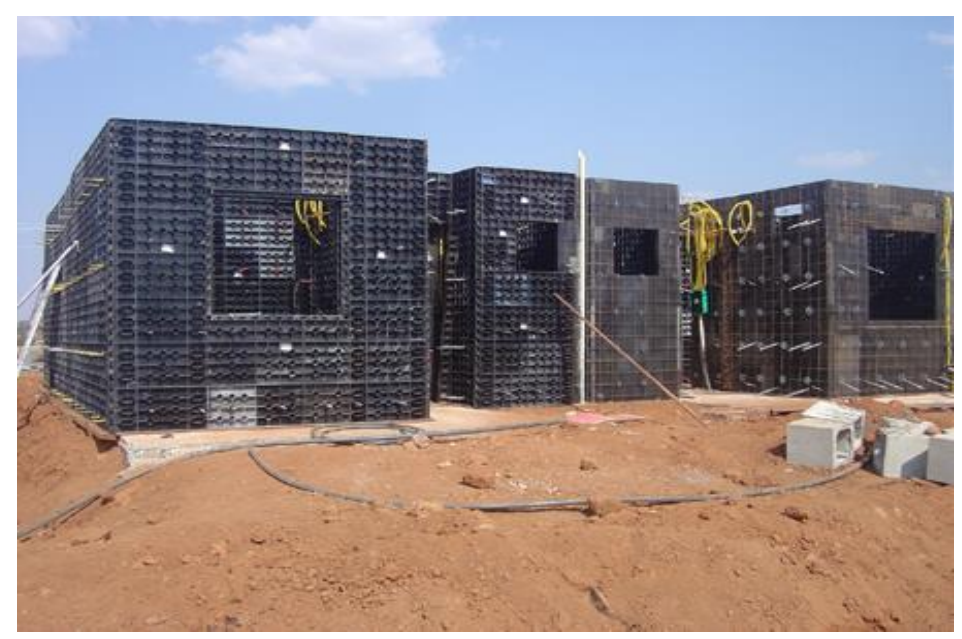

Figura 12 - Fôrmas plásticas

Fonte: (BRASIL ENGENHARIA, 2021)

Fôrmas mistas: utiliza esquadrias metálicas e chapas de madeira compensada ou material sintético para o acabamento na peça concretadas. As esquadrias podem ser de aço ou alumínio e esse tipo de fôrma oferece a vantagem de permitir as medidas flexíveis, adaptando-se a diferentes projetos.

Por outro lado, esses painéis são mais pesados do que as outras opções, e requerem a troca das chapas de compensado. É recomendado substituir as chapas de compensado a cada 30 utilizações. 


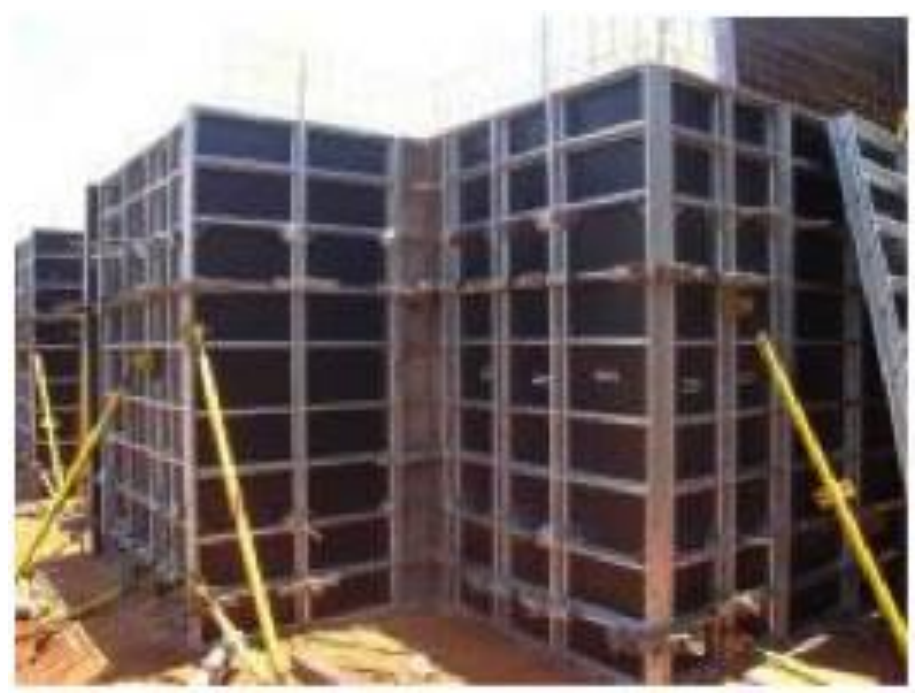

Figura 13 - Fôrmas mistas

Fonte: (COMUNIDADE DA CONSTRUÇÃO, 2021)

A Associação de Cimento Portland, diz que, a utilização do desmoldante adequado é essencial para a manutenção dos painéis, para terminar com um acabamento superficial da peça onde será aplicado o concreto, assim, não comprometendo a aderência do revestimento. Para cada modelo de fôrma requer um tipo específico de desmoldante, por isso, a sua escolha deve ser rigorosa.

\section{ACABAMENTO}

Logo após a desforma, se a concretagem foi bem executada, o acabamento é suficiente para que as paredes possam ser pintadas ou receberem qualquer tipo de revestimento. Caso contrário, se o acabamento do final do concreto não ser perfeito, será feito a correção das falhas e emendas com argamassa ou até mesmo com um material a base de gesso.

Nas paredes internas são mais comuns o uso de massa corrida e logo em seguida a aplicação do látex. Tanto na parte interna, quanto na externa, podem receber vários tipos de revestimento, como por exemplo: textura acrílica, grafiato, lamato, revestimento cristal, ou uso de cerâmica, assim, escondendo pequenas imperfeições nas paredes. Para a aplicação de qualquer tipo de revestimento é ideal seguir as especificações técnicas de cada produto. Para ter um melhor acabamento. 
É importante ressaltar que antes de aplicar qualquer tipo de complementos e revestimento nas paredes, é ideal aguardar a cura total do concreto.

\section{CONCLUSÃO}

Esse artigo referiu-se ao método construtivo Parede de Concreto, mostrando a sua execução, suas vantagens e desvantagens, os modelos de fôrmas mais utilizadas, as características e as especificações do concreto segundo a NBR 16055:2012 e o seu acabamento.

Quanto a qualidade do acabamento na parede, as formas de alumínios são mais vantajosas. Sua estrutura é mais rígida e os painéis mais duráveis.

O uso deste método gera um custo inicial elevado, porém quando se observa as vantagens o investimento é compensado.

Com o alto crescimento no setor da construção civil nos últimos anos, o sistema construtivo abordado neste artigo, é uma ótima alternativa para empreendimento com um grande nível de repetitividade, assim, podendo atender uma alta demanda de obras e com maior rapidez.

Pode-se concluir que o sistema comparado ao método convencional, a alvenaria, apresenta algumas vantagens, sendo as principais delas: menor desperdício de matéria prima, rápida execução, e não é necessária uma mão de obra especializada.

Haverá um grande crescimento na utilização deste sistema construtivo nos próximos anos. Pois, Paredes de Concreto vem sendo reconhecido cada vez mais pelas construtoras em todo Brasil.

\section{REFERENCIAS BIBLIOGRÁFICAS}

https://repositorio.ufmg.br/bitstream/1843/30921/1/Monografia Bernardo\%20Ba rroso Rev06\%20-\%20Final.pdf > Acesso em: 12 abr. 2021. 
ASSOCIAÇÃO BRASILEIRA DE NORMAS TÉCNICAS. NBR16055: Paredes de concreto. Rio de Janeiro, 2012. 35 p. >Acesso em: 12 abr. 2021.

BRASIL ENGENHARIA. Fôrmas de plásticos para paredes de concreto: Soluções para a construção civil. Disponível em:

http://www.brasilengenharia.com/portal/noticias/destaque/7583-formasplasticas-para-paredesde-concreto-solucao-para-a-construcao-civil >Acesso em: 23 set. 2021.

COMUNIDADE DA CONSTRUÇÃO. Paredes de concreto. Disponível em: http://www.comunidadedaconstrucao.com.br/sistemas-construtivos/2/paredede-concreto/. >Acesso em: 13 abr. 2021.

CORAIL, J. A. C; Actualización de tipologias estructurales usadas em edifícios de hormigón armado em Chile. 2007. Disponível em: https://repositorio.uchile.cl/bitstream/handle/2250/104697/calderon\%20 j.pdf?s equence=3\&isAllowed=y. >Acesso em: 13 abr. 2021.

CORSINI, Rodnei. Paredes normatizadas. Téchne. São Paulo, ed. 183, ano 20, p. 40- 46, jun. 2012. Acesso em: 07 jun. 2021. >Acesso em: 13 abr. 2021.

GUERRA, Ruy. Paredes de concreto passo a passo. 2013. Disponível em: https://www.printfriendly.com/p/g/rsUpnU. >Acesso em: 10 jun. 2021.

MISURELLI, Hugo; MASSUDA, Clovis. Como construir: paredes de concreto. Revista Téchne, 2009. >Acesso em: 07 jun. 2021.

NEVES, Antonio. Quais são as formas para paredes de concreto mais usadas? 07/02/2021. Disponível em: https://www.blok.com.br/blog/formas-paraparedes-de-concreto. >Acesso em: 23 set. 2021.

NEOFORMAS. Para concreto. Disponível em:

https://www.neoformas.com.br/forma-aluminio >Acesso em: 23 set. 2021.

PONZONI, Jessica. Paredes de concreto moldadas in loco: verificação do atendimento às recomendações da norma NBR16055/2012 nos procedimentos executivos em obra de edifício residencial. 2013. Disponível em:

https://www.lume.ufrgs.br/bitstream/handle/10183/96297/000915045.pdf?seque nce. $>$ Acesso em: 13 abr. 2021.

SACHT, Helenice Maria. Painéis de vedação de concreto moldados in loco: avaliação de desempenho térmico e desenvolvimentos de concretos. 2008. 
Disponível em: https://www.teses.usp.br/teses/disponiveis/18/18141/tde17102008-114925/publico/HeleniceSacht.pdf. >Acesso em: 07 jun. 2021.

SANTIN, Eder. Passo a passo de execução - Parede de Concreto. 2011. Disponível em: https://pt.slideshare.net/esantin2/passo-a-passo-de-execuoparede-de-concreto. >Acesso em: 10 jun. 2021.

CIMENTO ITAMBÉ. Cresce uso de paredes de concreto entre países latinos. 2018. Disponível em: https://www.cimentoitambe.com.br/massacinzenta/cresce-uso-de-paredes-de-concreto-entre-paises-latinos/. >Acesso em: 23 set. 2021. 